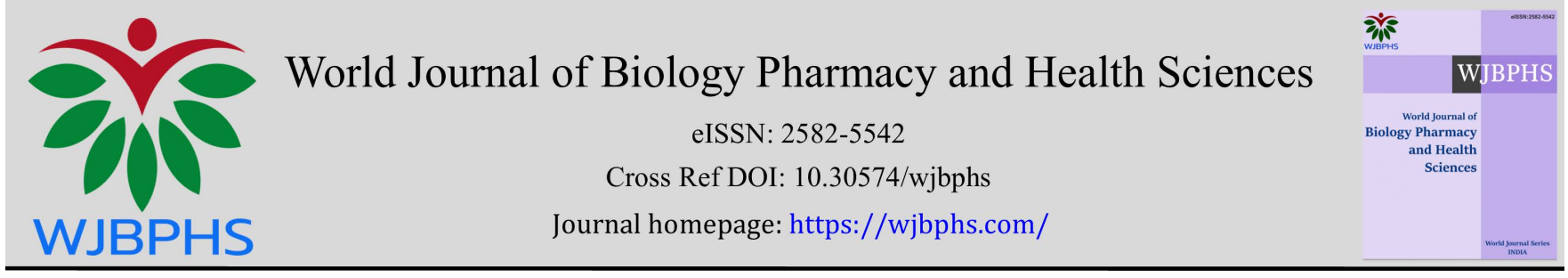

(REVIEW ARTICLE)

\title{
Bioactivity and uses of Cnidoscolus aconitifolius (Mill.) I.M. Johnst
}

\author{
Marina Silalahi * \\ Prodi Pendidikan Biologi, Fakultas Keguruan dan Ilmu Pendidikan, Universitas Kristen Indonesia, Jl. Mayjen Sutoyo No. 2 \\ Cawang, Jakarta Timur. 13510.
}

World Journal of Biology Pharmacy and Health Sciences, 2021, 07(03), 057-064

Publication history: Received on 10 August 2021; revised on 16 September 2021; accepted on 18 September 2021

Article DOI: https://doi.org/10.30574/wjbphs.2021.7.3.0097

\begin{abstract}
Cnidoscolus aconitifolius has been long used by ethnic groups in Indonesia for vegetables and traditional medicine. This study aims to explain the benefits of $C$. aconitifolius for food and its bioactivity. The method for writing is library research on scientific articles published online at Google Scholar by using the keywords: uses of C. aconitifolius and bioactivity of C. aconitifolius. All available articles were synthesized to provide comprehensive information on C. aconitifolius for food and its bioactivity. $C$. aconitifolius has two to three times more nutrients than spinach, spinach, Chinese cabbage, and lettuce. Cnidoscolus aconitifolius bioactivity includes antimicrobial, antidiabetic, hepatoprotective, antioxidant, antihypercholetrol, analgesic, antianemia, and kidney protection. Cnidoscolus aconitifolius leaves contain macronutrients such as carbohydrates, proteins, fats, vitamins and minerals so that they have the potential to be developed for cheap and easily available food. On the other hand, C. aconitifolius also contains anti-nutrients such as phytate and oxalate but with proper processing the antinutrients will be degraded.
\end{abstract}

Keywords: Cnidoscolus aconitifolius; Antimicrobial; Diabetes mellitus; Bioactivity

\section{Introduction}

Plants are one of the alternatives used by humans for the treatment of various diseases, especially in developing countries such as Indonesia. Exploration of nutraceutical plants, which are food ingredients and gives a healthy effect, continues to be carried out. Cnidoscolus aconitifolius has long been used by various ethnic groups as a vegetable [1] and in traditional medicine. This plant is easy to find in the surrounding environment such as yards, roadsides, and cultivated land [2]. The beautiful leaf structure with dense branching pattern makes C. aconitifolius often used as decoration and living fence.

The use of plants as food ingredients is related to their nutritional content, while their use as traditional medicine is related to their secondary metabolite content [3]. Cnidoscolus aconitifolius has two to three times more nutrients than spinach (Amaranthus sp.), cabbage (Brassica sp), and lettuce (Lactuca sp) [4]. Fresh leaves contain protein (4.38\%), fat (1.20\%), fiber (2.39\%) and carbohydrates (85.36\%) [5] or nutrients (mg/100 g) namely carbohydrates (41.895), protein (7.68), and crude fat (1.145) and crude fiber (31.165) [4]. In addition, C. aconitifolius also contains essential amino acids, vitamins such as carotene, niacin, riboflavin, and thiamine [4]. The mineral content includes sodium, potassium, calcium, magnesium, zinc, copper and iron [4,6]. C. aconitifolius leaves are rich in vitamin A, vitamin B2, vitamin B1, vitamin B9, vitamin C, vitamin D, vitamin E and vitamin $\mathrm{K}[4,7]$, vitamin B3, vitamin B6, vitamin B12, and vitamin E [7].

\footnotetext{
* Corresponding author: Marina Silalahi; E-mail:marina_biouki@yahoo.com

Prodi Pendidikan Biologi, Fakultas Keguruan dan Ilmu Pendidikan, Universitas Kristen Indonesia, Jl. Mayjen Sutoyo No. 2 Cawang, Jakarta Timur.
}

Copyright (C) 2021 Author(s) retain the copyright of this article. This article is published under the terms of the Creative Commons Attribution Liscense 4.0. 
Besides being used as food, C. aconitifolius is also used for traditional medicine. Bautista-Robles et al [8] stated that $C$. aconitifolius is efficacious for treating skin irritation, wounds, insect bites, and snake bites. C. aconitifolius was reported as a potential antimicrobial agent [6], having antitumor, antidiabetic, antimicrobial and hematopoietic activity [4]. The bioactivity is related to its secondary metabolites such as terpenoids, alkaloids, coumarins, phenolics and flavonoids $[9,10]$. The content of secondary metabolites is influenced by the processing process. Babalola and Alabi [11] stated that the concentration of alkaloids and flavonoids in the fresh leaf extract was higher than that of the boiled leaves, but the content of phytate and tannins decreased significantly in the boiled leaves compared to the fresh leaves.

Although plants as traditional medicines are relatively safe, knowledge of processing processes and dosages needs to be increased so that side effects can be minimized. Lennox and John [5] reported that C. aconitifolius contains antinutrients in the form of phytic acid $(60.44 \mathrm{mg} / 100 \mathrm{~g})$, oxalate $(40.30 \mathrm{mg} / \mathrm{g})$ but not detrimental to health. Oyeyemi and Ajani [12] stated that the use of 20 or $30 \%$ aqueous extract of $C$. aconitifolius leaves for four weeks reduced testosterone concentrations in sheep so that in the long term it could lead to decreased sexual function, decreased libido and erectile dysfunction, triggering anemia and finally infertility in male animals. However, the effective use of $C$. aconitifolius should be used with caution because of the possibility of dose- and time-dependent toxicity [13]. Therefore, it is necessary to provide comprehensive information on the bioactivity of $C$. aconitifolius. This study aims to explain the utilization and bioactivity of $C$. aconitifolius.

\section{Methods}

The method of writing this article is a literature study that has been published online on Google Scholar. The keywords to search for scientific articles are $C$. aconitifolius, uses of $C$. aconitifolius, and bioactivities of $C$. aconitifolius. The information was analyzed and synthesized so as to explain the benefits and bioactivity of $C$. aconitifolius comprehensively.

\section{Results and discussion}

\subsection{Botany of Cnidoscolus aconitifolius (Mill.) I.M. Johnst}

Euphorbiaceae is one of the large families estimated has 334 genera [14] has more than 8,000 species [15], spread mainly in the tropics in several types of vegetation and habitats. Cnidoscolus is a genus that is used as food and traditional medicine. On the island of Java, the genus Cnidoscolus Pohl. has only one species, namely C. aconitifolius (but has 2 subspecies, namely C. aconitifolius subsp. aconitifolius and C. aconitifolius subsp. Polyanthus [2].

C. aconitifolius is shrubby to small tree, up to $4 \mathrm{~m}$ high, with milky latex. Terete trunk, with large scars; bark fawn, cracked, with milky latex. Glossy green branches, white patches, with or without stinging hairs. Stipules narrow lanceolate, 2-3 $\times 1 \mathrm{~mm}$, apex acuminate, brown, early caducous. Leaves simple, alternate with slender petioles, 5.5-28 cm long, green, glabrous; lamina 3- lobed or 5-7(-9)-partitioned, 6-23 × 7-30 cm; dark green above, yellowish green below, sub-coriaceous; Nectar glands are present at the base. flower terminal, dichasial sub-umbelliform; stalks up to $29 \mathrm{~cm}$ long with few short pilose hairs, green; triangular-linear bracts and bracteoles. Stamina salverform flower, congenital sepal petaloid, 5-lobed; tube 6-10 mm long, green; obovate to orbicular lobe, 3-4 × 4-5 mm, white, green below; stamens 10, 2- coiled, outer stamens $4 \mathrm{~mm}$ long; inner stamen length $7 \mathrm{~mm}$; filiform filaments, white; anthers oblong, 1-2 × 0.5-1 mm, white, dorsibasifixation; Pistillode present, stringy, white. Pistil campanulate flowers, petaloid 5 petals, free, lobes oblong, 6-7 $\times 3 \mathrm{~mm}$, white; 5-lobed disc, glabrous, white; ovary superior, ellipsoid, $3 \mathrm{~mm}$ long, triloculate, glossy green, glabrous; very short force, $\pm 1 \mathrm{~mm}$; stigma forked, white, glabrous. Fruit capsule, unbroken, ovoid, 1, × $0.6 \mathrm{~cm}$ (Figure 1). Seeds fail [2].

The cultivated $C$. aconitifolius variety has more branches and leaves, and the leaves are softer and have fewer trichomes than the wild variety. This difference may be reinforced by the fact that desirable traits (number of branches and leaves) were negatively correlated with undesirable traits (trichome number and toughness) [16]. 


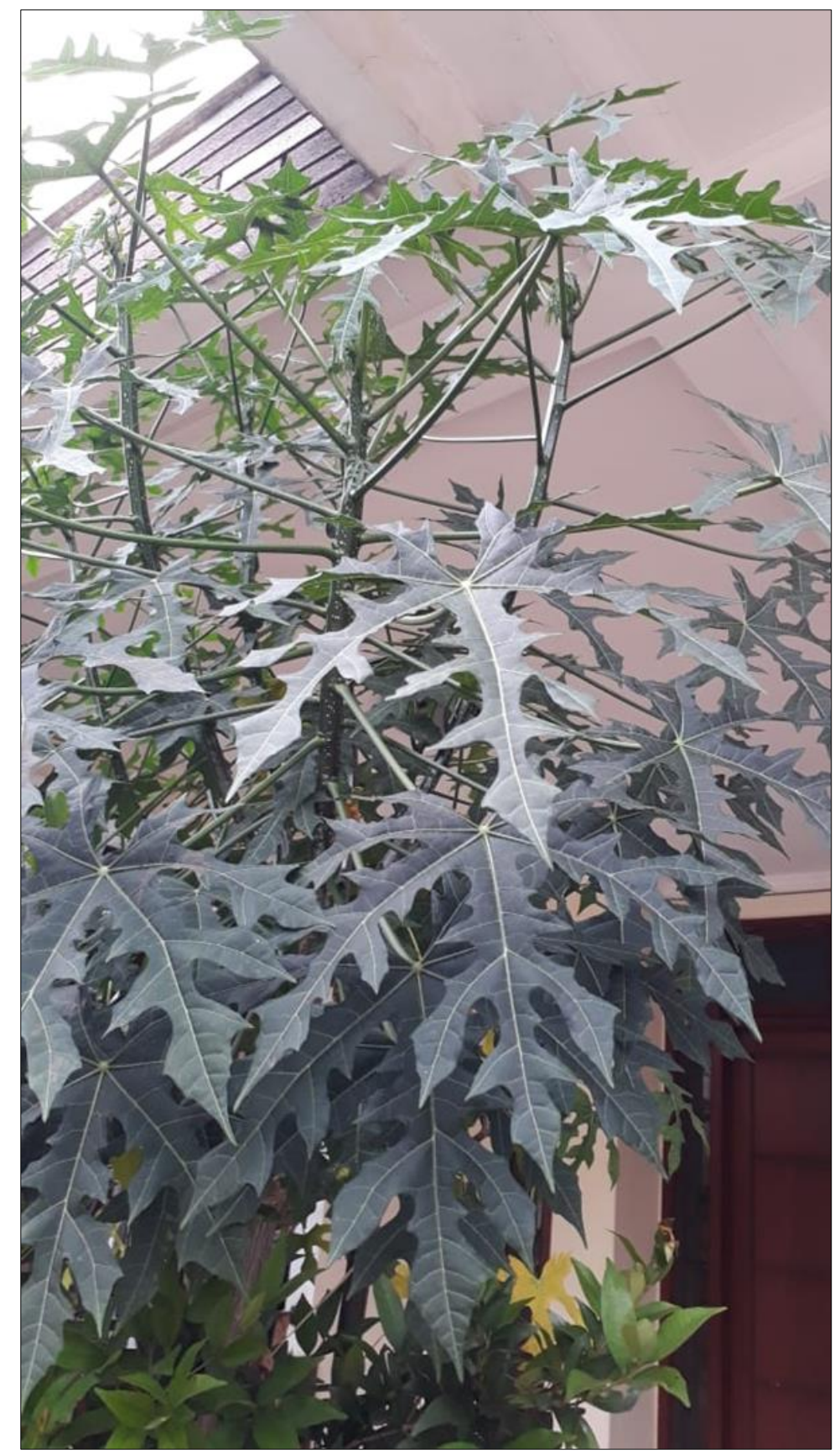

Figure 1 The habitus and leaves Cnidoscolus aconitifolius

\section{Uses and Bioactivities}

The empirically C. aconitifolius has long been used as food and traditional medicine. The genus Cnidoscolus has analgesic, anti-inflammatory, antibiotic, diuretic, anticancer [17], anti-free radical [9] effects. C. aconitifolius is a potential antimicrobial agent for the treatment of infections [6] and has antitumor, antidiabetic, antimicrobial and hematopoietic activity [4]. We will discuss further about the bioactivity of $C$. aconitifolius such as anti-microbial, antidiabetic mellitus, hepatoprotective, antioxidant, anti-hypercholesterolemia, analgesic, antianemia, kidney protection.

\subsection{Anti-microbial}

Antimicrobial compounds are compounds that inhibit the growth of microorganisms such as bacteria and fungi. The bioactivity of $C$. aconitifolius leaves as antimicrobial has been reported by Fagbohun et al [4] and Ogbu and Igboanusi [18], Oyagbemi et al [19], Hamid et al [20], and Adeniran et al [21]. The C. aconitifolius extract inhibited the growth of bacteria such as Escherichia coli [4,5,18-21], Psuedomonas aeruginosa, Staphylococcus aureus [4,18-20], Klebsiella 
pneumonia [4,20], P. fluorescence [18], Klebsiella, Salmonella enterica, Gallinarum, Candida albicans [19], Bacillus subtilis [21], Salmonella typhi and Streptococcus pyogenes [5]. The inhibition zone of the $C$. aconitifolius extract was influenced by the type of microbe, contact time, and concentration. Bacterial sensitivity to $C$. aconitifolius extract varied, namely $P$. fluorecence $>$ P. aeruginosa $>S$. aureus $>$ E. coli [18]. The inhibition zones of $C$. aconitifolius leaf methanol extract with concentrations of $125 \mathrm{mg} / \mathrm{ml}$ and $500 \mathrm{mg} / \mathrm{ml}$ were different, namely Klebsiella pneumonia $(1.0 \mathrm{~mm} \mathrm{-} 4.5 \mathrm{~mm})$, Psuedomonas aeruginosa (1.5 mm - $5.0 \mathrm{~mm})$, Escherichia coli $(1.0 \mathrm{~mm}-3.5 \mathrm{~mm})$, Staphylococcus aureus $(1.0 \mathrm{~mm}-6.5)$ [4]. The C. aconitifolius extract $10 \mathrm{~g} / \mathrm{ml}$ resulted in a zone of inhibition in Salmonella typhi (20.5 mm) and Streptococcus pyogenes $(26 \mathrm{~mm})$. The zones of inhibition of standard antibiotics were gentamicin $10 \mathrm{~g} / \mathrm{ml}$ against E. coli $(19 \mathrm{~mm})$, ofloxacin at $5 \mathrm{~g} / \mathrm{ml}$ against $K$. pneumoniae $(21 \mathrm{~mm})$ and methicillin at $10 \mathrm{~g} / \mathrm{ml}$ against S. pyogenes, K. pneumonia and E. coli $(16 \mathrm{~mm})[5]$.

In addition to inhibiting bacterial growth, $C$. aconitifolius extract also inhibited fungal growth. The crude extract of $C$. aconitifolius leaves inhibited the growth of fungi (Candida albicans, Aspergillus niger, Penicillium notatum and Rhizopus stolonifer [20]. The inhibition zones of $C$. aconitifolius methanol extract with concentrations of $125 \mathrm{mg} / \mathrm{ml}$ and 500 $\mathrm{mg} / \mathrm{ml}$ inhibited the growth of different fungal mycelium such as Aspergillus tamari (22\% - 100\%) within 24 hours [4]. The extract inhibited $A$. niger by $9 \%(31.25 \mathrm{mg} / \mathrm{ml})$ and $91 \%(500 \mathrm{mg} / \mathrm{ml})$ after 24 hours [4]. These differences are related to differences in cell wall composition, metabolism, properties, resistance to antibiotics or local environmental factors [18]. The bioactivity of the $C$. aconitifolius extract as an antimicrobial is related to the content of its secondary metabolites. Extracts of n-hexane, ethyl acetate and methanol from the aerial part of $C$. aconitifolius has anthraquinones, glycosides, steroids, flavonoids, tannins, saponins and terpenoids [20] while aqueous and ethanolic extracts of $C$. aconitifolius leaves did not contain flavonoids, anthraquinones, and anthraquinones [22].

\subsection{Anti-diabetes Mellitus}

Diabetes mellitus is a type of metabolic disorder that causes blood glucose levels to be above normal. Diabetes mellitus has been associated with several complications caused by oxidative stress [23]. One of the problems of diabetes pharmacotherapy is an effective and safer approach to the management of prediabetics and diabetes [13]. Changes in body weight, blood glucose and serum lipids were assessed as indicators of the severity of diabetes and its complications [24]. Compounds used as anti-diabetes mellitus are compounds that are able to inhibit the breakdown of carbohydrates into glucose or have hypoglycemic properties or compounds that stimulate the pancreas to produce insulin [24].

Cnidoscolus aconitifolius has hypoglycemic properties so that it can be used as a medicine for diabetes mellitus [24]. In the laboratory, Streptozotocin (STZ) is a compound used to stimulate diabetic rats. The $C$. aconitifolius leaf aqueous extract given orally every day at concentrations of 400,600 and $800 \mathrm{mg} / \mathrm{kg}$ BW showed a decrease in blood sugar levels in STZ-induced rats [7]. The C. aconitifolius leaf extract with concentrations of 100, 150 and $200 \mathrm{mg} / \mathrm{Kg}$ reduced diabetic blood glucose 41,76; 71.11 and 73.46 [13]. The diabetic rats induced with STZ, then treated with $C$. aconitifolius leaf extract (100-200 mg/kg bw) increased liver enzymes in comparison with $10 \mathrm{mg}$ glibenclamide (standard drug) indicating that C. aconitifolius has an adverse effect on the liver [25]. C. aconitifolius has insulinogenic properties that may stimulate inactive cells to secrete insulin. Islets of Langerhans were preserved in a group of mice treated with $C$. aconitifolius [26]. The ethyl acetate fraction of leaves $C$. aconitifolius inhibited the activity of -amylase and -glucosidase, acetylcholinesterase, butyrylcholinesterase, monoamine oxidase, tyrosinase, arginase, Ecto-5'-nucleotidase, phosphodiesterase-5, angiotensin-I-converting enzyme and increased the activity of $\mathrm{Na}^{+} / \mathrm{K}^{+}$-ATP ase [27].

\subsection{Hepatoprotective}

Hepatoprotective is a compound that has a therapeutic effect, to restore, maintain, and treat damage to liver function [28]. The $C$. aconitifolius had a protective effect of leaf extract against carbon tetrachloride $\left(\mathrm{CCl}_{4}\right)$-induced hepatotoxicity and chemotoxicity in experimental animals [29]. The $\mathrm{CCl}_{4}$ also caused significant increases in serum transaminases (ALT and AST) and phosphatase (ALP), resulting in significant increases in serum blood urea nitrogen (BUN) and creatinine compared to normal mice. Pre-exposure to $C$. aconitifolius leaf extract greatly reduced the effect of $\mathrm{CCl}_{4}$ on blood parameters and ameliorated liver damage enzymes (ALT, AST and ALP) [29]. The addition of $C$. aconitifolius leaf aqueous extract to the rat diet at 100,200 , and $400 \mathrm{mg} / \mathrm{kg}$ body weight for 28 days histopathological showed that the organs of the animals studied were not damaged [30].

\subsection{Antioxidants}

Stress, excessive consumption of processed foods will cause oxidative stress and damage to genetic material which directly or indirectly causes various diseases of diabetes, hypertension, cancer and metabolic syndrome [31]. Antioxidants are compounds that have activity to inhibit free radicals. Aqueous and methanol extracts of $C$. aconitifolius leaves protected mice induced by oxidative stress and genotoxic damage from exposure to low-dose arsenic and 
streptozotocin. The $C$. aconitifolius contains ferulic acid, protocatechuic acid, riboflavin, kaempferol and beta carotene which are thought to be associated with a protective effect against genotoxic damage [31].

The hydroalcoholic extract of $C$. aconitifolius leaves contains phenolic compounds such as gallic acid, vanillic acid, vanillin, chlorogenic acid, caffeic acid, ferulic acid, rosmarinic acid, p-coumaric acid, resveratrol, luteolin and apigenin. The $C$. aconitifolius boiled leaves have higher antioxidants than raw leaves. Boiled leaves have a higher polyphenol content so that they become a source of antioxidants [32]. The bioactivity as an antioxidant is related to the content of phenolic compounds [27,32]. The ethyl acetate fraction of $C$. aconitifolius leaves contains coumaric acid, amentoflavones, hesperidin, protocatechuic acid, kaempferol, dihydromyricetin, quercetin, and rutin. The C. aconitifolius leaves have extraordinary antioxidant potential [27].

Ethyl acetate and methanol extract of $C$. aconitifolius leaves showed antioxidant activity and free radical scavenging DPPH (2,2-difenil-1-pikrilhidrazil) IC 12.14 and $93.85 \mathrm{~g} / \mathrm{ml}$, respectively. Phytols were the most abundant constituents in the extracts of $n$-hexane, ethyl acetate and methanol with the corresponding abundance percentages of $41.07 \%$, $35.42 \%$ and $35.07 \%$ [20]. The $C$. aconitifolius extract reduces oxidative stress by increasing the activity of several antioxidant enzymes and can prevent cell death due to lipid peroxidation [33].

\subsection{Anti-hypercholesterolemia}

Hypercholesterolemia is a condition characterized by high levels of cholesterol in the blood and if it accumulates and narrows the blood vessels, it directly or indirectly affects the circulatory system. The C. aconitifolius leaf extract has antihypercholesterolemic potential [34]. Rats given $200-800 \mathrm{mg} / \mathrm{kg}$ BW aqueous and ethanol extract of $C$. aconitifolius leaves showed a significant reduction in total cholesterol (TC), low density lipoprotein (LDL) and triglyceride (TG) with an increase in high density lipoprotein (HDL) which was dose dependent and therefore beneficial in the treatment of coronary heart disease [34].

\subsection{Anti-anemia}

Anemia is a condition when the number of red blood cells is lower than normal. Iron supplements can be used for iron and vitamin B deficiency. Onuoha et al [35] stated that anemic rats then given 5-15 ml of C. aconitifolius leaf raw juice showed a significant increase in hemoglobin, solid cell volume, red blood cells and white blood cells. The bioactivity is thought to be related to the mineral and vitamin content in C. aconitifolius leaves. The C. aconitifolius has vitamin B3, vitamin B6, vitamin B12 [7] and minerals Sodium, Potassium, Calcium, Magnesium, Zinc, Copper, Iron [4,6].

\subsection{Lower Testosterone}

Testosterone is one of the androgen hormones produced by the testes in males which is very important in reproduction. Lowering the testosterone hormone is one way to regulate birth. Lucky and Festus [36] reported that rats fed $1.5 \mathrm{~g} / \mathrm{kg}$ body weight showed significantly reduced testosterone levels and significantly increased levels of luteinizing hormone $(\mathrm{LH})$ and follicle stimulating hormone (FSH). The testosterone/estrogen ratio also increased depending on the duration of treatment [36]. The bioactivity is thought to be related to the $C$. aconitifolius steroid content. The $C$. aconitifolius leaves contain tannins, saponins, cyanogenic glycosides, alkaloids, phenols, flavonoids, and steroids [30].

\subsection{Overcoming Stomach Ulcers}

Ulcers are wounds caused by damage to the epithelium and basement membrane. The $C$. aconitifolius in traditional medicine for the treatment of gastric ulcers. The methanol extract of $C$. aconitifolius leaves has gastro-protective activity in rats induced by diclofenac in causing gastric mucosal lesions by increasing the ulcer index inhibition against gastric mucosal damage induced by diclofenac [37].

\subsection{Analgesic}

Various human diseases are accompanied by pain, therefore one of the goals of drug administration is to reduce pain. Compounds used to reduce pain are called analgesics. In laboratory experiments, pain was induced by formalin, acetic acid and hot plate tests. The $C$. aconitifolius extract (100 or $200 \mathrm{mg} / \mathrm{kg}$ b.w.) inhibited rat acetic acid-induced irritation comparable to indomethacin $(10 \mathrm{mg} / \mathrm{kg} \mathrm{bw})$. Carrageenan-induced edema was significantly inhibited by the extract (100 and $200 \mathrm{mg} / \mathrm{kg} \mathrm{bw)} \mathrm{compared} \mathrm{to} \mathrm{control} \mathrm{mice} \mathrm{[38].}$

\subsection{Anti-cancer}

The $C$. aconitifolius in ethnomedicine is used to treat cancer. Methanol extract of leaves, stems, and bark of CA roots has the effect of treating breast cancer (MCF-7) and lung (NCI-H460). Leaf extract at a concentration of $100 \mathrm{~g} / \mathrm{mL}$ showed 
remarkable growth inhibition against breast cancer and lung cancer in vitro. The C. aconitifolius extract contains saponins, terpenes, cardiac glycosides, and phenolic compounds [39].

\subsection{Protect The Kidney}

Rats given $C$. aconitifolius leaf methanol extract (MECA) at doses (100 and $200 \mathrm{mg} / \mathrm{kg}$ ) had a renal protective effect by attenuating the oxidative stress function caused by chronic ethanol administration. Administration of $C$. aconitifolius leaf methanol extract (MECA) in mice significantly weakened the biochemical index above close to normal. Ethanol poisoning caused a significant decrease in the levels of catalase (CAT), superoxide dismutase (SOD) and reduced glutathione (GSH) in the rat kidney. MECA attenuated ethanol-induced increases in renal serum and MDA, and also improved the antioxidant status of mice by increasing CAT, SOD and GSH levels [40].

\section{Conclusion}

Cnidoscolus aconitifolius bioactivity includes antimicrobial, antidiabetic, hepatoprotective, antioxidant, antihypercholetromia, analgesic, antianemia, and kidney protection. The $C$. aconitifolius leaves contain macronutrients such as carbohydrates, proteins, fats, vitamins and minerals so that they have the potential to be developed for cheap and easily available food. On the other hand, $C$. aconitifolius also contains anti-nutrients such as phytate and oxalate but with proper processing the antinutrients will be degraded.

\section{Compliance with ethical standards}

\section{Acknowledgments}

I express my gratitude to the Indonesian Christian university for funding this research.

\section{References}

[1] Silalahi M. Keanekaragaman tumbuhan bermanfaat di pekarangan oleh Etnis Sunda di Desa Sindang Jaya Kabupaten Cianjur Jawa Barat. Jurnal Pendidikan Matematika dan IPA. 2019; 10(1): 88-104.

[2] Irsyam ASD, Hariri MM, Irwanto RR, Peniwidiyanti. Marga Cnidoscolus Pohl (Euphorbiaceae) di Jawa the Genus Cnidoscolus Pohl (Euphorbiaceae) in Java. Al-Kauniyah: Jurnal Biologi. 2020; 13(1): 76-86.

[3] Orji OU, Ibiam UA, Aja PM, Ugwu Okechukwu PC, Uraku AJ, Aloke C, Obasi OD, Nwali BU. Evaluation of the phytochemical and nutritional profiles of Cnidoscolus aconitifolius leaf collected in Abakaliki South East Nigeria. World Journal of Medical Sciences. 2016; 13(3): 213-217.

[4] Victor M, Abbey PA, Joseph Y, Jonathan Z, Bobai YK, Maria O. Underexploited tropical plant with promising economic value and the window of opportunities for researchers: Cnidoscolus aconitifolius. American Journal of Food Science and Nutrition Research. 2016; 3(6): 177-187.

[5] Lennox JA, John GE. Proximate composition, antinutrient content and antimicrobial properties of Cnidoscolus aconitifolius leaves. Asian Food Science Journal. 2018; 5(4): 1-6.

[6] Fagbohun ED, Egbebi AO, Lawal OU. Phytochemical screening, proximate analysis and in-vitro antimicrobial activities of methanolic extract of Cnidoscolus aconitifolius leaves. International Journal of Pharmaceutical Sciences Review and Research. 2012; 3(1): 005.

[7] Obichi EA, Monago CC, Belonwu DC. Effect of Cnidoscolus aconitifolius (Family Euphorbiaceae) aqueous leaf extract on some antioxidant enzymes and haematological parameters of high fat diet and streptozotocin induced diabetic wistar albino rats. J. Appl. Sci. Environ. Manage. 2015; 19(1): 201-209.

[8] Bautista-Robles V, Guerrero-Reyes G, Sánchez-Torres GI, de Jesús Parada-Luna F, Barrios-Gutiérrez JJ, VázquezCerero D, G Martínez-Sala, JI Siliceo-Murrieta, RAM González-Villoria, H Keita. Cnidoscolus aconitifolius: therapeutic use and phytochemical properties. Literature review. Rev. Fac. Med. 2020; 68(3): 446-52.

[9] Somade OT, Akinloye OA, Ugbaja RN, Idowu MA. Cnidoscolus aconitifolius leaf extract exhibits comparable ameliorative potentials with ascorbate in dimethylnitrosamine-induced bone marrow clastogenicity and hepatotoxicity. Clinical Nutrition Experimental. 2020; 29: 36-48. 
[10] Kuri-García A, Chávez-Servín JL, Guzmán-Maldonado SH. Phenolic profile and antioxidant capacity of Cnidoscolus chayamansa and Cnidoscolus aconitifolius: A review. Journal of Medicinal Plants Research. 2017; 11(45): 713727.

[11] Babalola JO, Alabi 00. Effect of processing methods on nutritional composition, phytochemicals, and anti-nutrient properties of chaya leaf (Cnidoscolus aconitifolius). African Journal of Food Science. 2015; 9(12): 560-565.

[12] Oyagbemi AA, Ogunleye AO, Lawal TO, Azeez IO. The effect of Cnidoscolus aconitifolius on multi-drug resistant micro-organisms. African Journal of Biotechnology. 2011; 10(3): 413-415.

[13] Samuel I, Arthur N, Jude E, Henrietta C. Antihyperglycaemic efficacy of Cnidoscolus aconitifolius compared with glibenclamide in alloxan-induced diabetic wistar rats. International Research Journal of Medical Sciences. 2014; 2(3): 1-4.

[14] Webster GL, Armbruster WS. A synopsis of the neotropical species of Dalechampia (Euphorbiceae). Botanical Journal of the Linnean Society. 1991; 105: 137-177.

[15] Radcliffe-Smith A. Genera Euphorbiacearum. Royal Botanic Gardens, Kew. 2001; 464.

[16] Munguia-Rosas MA, Jacome-Flores ME, Bello-Bedoy R, Solıs-Montero V, Ochoa-Estrada E. Morphological divergence between wild and cultivated chaya (Cnidoscolus aconitifolius) (Mill.) I.M. Johnst. Genet Resour Crop Evol. 2019; 66: 1389-1398.

[17] Moura LFWG, da Silva Neto JX, Lopes TDP, Benjamin SR, Brito FCR, Magalhães FEA, Florean EOPT, de Sousa BDOB, Guedes MIF. Ethnobotanic, phytochemical uses and ethnopharmacological profile of genus Cnidoscolus spp. (Euphorbiaceae): A comprehensive overview. Biomedicine \& Pharmacotherapy. 2019; 109: 1670-1679.

[18] Ogbu HI, Igboanusi EC. Bacterial isolates from surgical wound infection and their susceptibility reaction to Cnidoscolus aconitifolius leaf extract and honey. Journal of Medicinal Plants Studies. 2019; 7(2): 163-170.

[19] Oyagbemi AA, Odetola AA, Azeez OI. Ameliorative effects of Cnidoscolus aconitifolius on anaemia and osmotic fragility induced by proteinenergy malnutrition. African Journal of Biotechnology. 2008; 7(11): 1721-1726.

[20] Hamid AA, Oguntoye SO, Negi AS, Ajao A, Owolabi NO. Chemical constituents, antibacterial, antifungal and Antioxidant activities of the aerial parts of Cnidoscolus aconitifolius. Ife Journal of Science. 2016; 18(2): 561-571.

[21] Adeniran OI, Olajide O0, Igwemmar NC, Orishadipe AT. Phytochemical constituents, antimicrobial and antioxidant potentials of tree spinach [Cnidoscolus aconitifolius (Miller) I. M. Johnston]. Journal of Medicinal Plants Research. 2013; 7(19): 1317-1322.

[22] Awoyinka OA, Balogun IO, Ogunnowo AA. Phytochemical screening and in vitro bioactivity of Cnidoscolus aconitifolius (Euphorbiaceae). Journal of Medicinal Plants Research. 2007; 1(3): 063-065.

[23] Azeez OI, Oyagbemi AA, Oyeyemi MO, Odetola AA. Ameliorative effects of Cnidoscolus aconitifolius on alloxan toxicity in Wistar rats. African Health Sciences. 2010; 10(3): 283-291.

[24] Mordi JC. Antidiabetic potential of the aqueous leaf extract of Cnidoscolus aconitifolius on streptozotocin (STZ) induced diabetes in wistar rat hepatocytes. Current Research Journal of Biological Science. 2012; 4(2): 164-167.

[25] Weleh II, Saronee F. Effects of hydromethanolic extract of Cnidoscolus aconitifolius (Euphorbiacaea) on body weight, some liver enzymes and histology in diabetic wistar rats. International Journal of Research and Scientific Innovation. 2019; 6(9): 190-194.

[26] Oladeinde FO, Kinyua AM, Laditan AA, Michelin R, Bryant JL, Denaro F, Makinde JM, Williams AL, Kennedy AP, Bronner Y. Effect of Cnidoscolus aconitifolius leaf extract on the blood glucose and insulin levels of inbred type 2 diabetic mice. Cellular and Molecular Biology. 2007; 53(1): 34-41.

[27] Ajiboye BO, Ojo OA, Okesola MA, Oyinloye BE, Kappo AP. Ethyl acetate leaf fraction of Cnidoscolus aconitifolius (Mill.) I. M. Johnst: antioxidant potential, inhibitory activities of key enzymes on carbohydrate metabolism, cholinergic, monoaminergic, purinergic, and chemical fingerprinting. International Journal of Food Properties. 2018; 21(1): 1697-1715.

[28] Armansyah TR, Sutriana A, Aliza D, Vanda H, Rahmi E. Aktivitas hepatoprotektif ekstrak etanol daun kucingkucingan (Acalypha indica L.) pada tikus putih (Rattus novergicus) yang diinduksi parasetamol. Jurnal Ilmiah Ilmu-Ilmu Peternakan. 2010; 13(6): 292-298.

[29] Saba AB, Oyagbemi AA, Azeez OI. Amelioration of carbon tetrachloride-induced hepatotoxicity and haemotoxicity by aqueous leaf extract of Cnidoscolus aconitifolius in rats. Nig. J. Physiol. Sci. 2010; 25: 139-147. 
[30] Akachukwu D, Okafor PN, Ibegbulem CO. Phytochemical content of Cnidoscolus aconitifolius and toxicological effect of its aqueous leaf extract in Wistar rats. J Invest Biochem. 2014; 1(1): 26-31.

[31] Guzmán EL, Castañeda CTB, Ocañas LG, Pescador MGN, Cruz FJM, Bañuelos JLR. Evaluation of antioxidant and protective effect against genotoxic damage of two extracts of chaya leaves (Cnidoscolus aconitifolius). Journal of Medicinal Plants Research. 2020; 14(10): 555-558.

[32] Godínez-Santillán RI, Chávez-Servín JL, García-Gasca T, Guzmán-Maldonado SH. Phenolic characterization and antioxidant capacity of alcoholic extracts from raw and boiled leaves of Cnidoscolus aconitifolius (Euphorbiaceae). Acta Botanica Mexicana. 2019; 126: 1-15.

[33] Ezebuiro I, Obiandu C, Saronee F, Obiandu AC. Effects of leaf extract of Cnidoscolus aconitifolius on serum lipids and oxidative stress markers of male wistar rats asian. Journal of Biochemistry, Genetics and Molecular Biology. 2020; 5(1): 47-52.

[34] Chukwu EC, Osuocha KU, Iwueke AV. Phytochemical profiling, body weight effect and anti-hypercholesterolemia potentials of Cnidoscolus aconitifolius leaf extracts in male albino rat. Journal of Pharmacognosy and Phytotherapy. 2020; 12(2): 19-27.

[35] Onuoha NO, Okafor AM, Eme PE, Odo EC. Haematinic effect of raw and boiled leaf juice of Cnidoscolus aconitifolius using cyclophosphamide-treated adult male albino rats. EC Nutrition. 2017; 7(5): 187-194.

[36] Lucky SC, OA Festus. Effects of aqueous leaf extract of chaya (Cnidoscolus aconitifolius) on pituitary-gonadal axis hormones of male Wistar rats. Journal of Experimental and Clinical Anatomy. 2014; 13(2): 35-40.

[37] Olivia NU, Happiness UC, Obinna OM. Protective effect of Cnidoscolus aconitifolius leaves against diclofenac induced gastric mucosal damage. Pak. J. Pharm. Sci. 2020; 33(2): 651-657.

[38] Onasanwo SA, Oyagbemi AA, Saba ADB. Anti-inflammatory and analgesic properties of the ethanolic extract of Cnidoscolus aconitifolius in rats and mice. Basic Clin Physiol Pharmacol. 2011; 22(1-2): 37-41.

[39] Ikpefan EO, Ayinde BA, Mudassir A, Farooq AD. Comparative in vitro assessment of the methanol extracts of the leaf, stem, and root barks of Cnidoscolus aconitifolius on lung and breast cancer cell lines. Turk J Pharm Sci. 2019; 16(4): 375-9.

[40] Adaramoye OA, Aluko A. Pharmacology and cell metabolism methanolic extract of Cnidoscolus aconitifolius attenuates renal dysfunction induced by chronic ethanol administration in wistar rats. Alcohol and Alcoholism. 2011; 46(1): 4-9. 